\title{
Pearls \& Oy-sters: May-Thurner syndrome as a cause of embolic stroke of undetermined source in a young patient
}

Andrés De León-Benedetti, MD, Erika T. Marulanda-Londoño, MD, and Amer M. Malik, MD, MBA

Neurology ${ }^{\circledR}$ 2019;92:e2507-e2509. doi:10.1212/WNL.0000000000007541
Correspondence

Dr. Malik

amalik@med.miami.edu

\section{Pearls}

- May-Thurner syndrome (MTS) is an anatomic abnormality consisting of chronic compression of the left common iliac vein (CIV) by the overlying right common iliac artery (CIA) and may predispose to local deep venous thrombus (DVT) formation, which in turn can result in paradoxical embolus in patients with a right-to-left cardiac shunt.

- Procoagulant states such as antiphospholipid antibody syndrome and homocysteinemia cause both arterial and venous thrombosis, while alterations in antithrombin III, factor $\mathrm{V}$ Leiden, prothrombin, and protein $\mathrm{C}$ relate mostly to venous thrombosis.

\section{Oy-sters}

- Presence of a patent foramen ovale (PFO) and a negative lower extremity venous Doppler in a patient with an embolic stroke of undetermined source should prompt the clinician to evaluate for proximal causes of emboli, such as MTS.

- Some PFO characteristics, such as the presence of an atrial septal aneurysm (ASA), excursion of the interatrial septum, and size of the shunt, suggest higher odds of a thromboembolic event.

- A clinical scoring tool, Risk of Paradoxical Embolism (RoPE), can help determine if a PFO is related to the stroke mechanism.

We report a case of embolic ischemic stroke in a young patient with PFO and ASA likely due to MTS.

\section{Case report}

A 35-year-old woman with migraine history and current intrauterine device presented to an outside hospital with abrupt onset left hemiparesis, numbness, and left field cut. She received IV recombinant tissue plasminogen activator (rtPA) and was transferred to our institution with symptom resolution by arrival. The patient was a lifetime nonsmoker, had not had any miscarriages, was not taking oral contraceptives, and had a body mass index of 24 . No family history of stroke or hypercoagulable disorder were reported. Neurologic examination was significant for minimal left-sided incoordination. MRI of the brain revealed acute infarct in the right lentiform, caudate nuclei, and corona radiata (figure, A and B). CT angiography of the head and neck, ECG, and 24-hour Holter monitor were unremarkable. Bloodwork and urine toxicology were normal aside from mild dyslipidemia. Hypercoagulable laboratory studies revealed borderline low antithrombin III activity at 79\% (80\%-117\%). Transthoracic echocardiogram with bubble study showed a right-to-left cardiac shunt and no other structural abnormality. Transesophageal echocardiogram revealed a PFO with ASA. Lower extremity venous Doppler did not show DVT. Given the embolic pattern of infarct and PFO with ASA, magnetic resonance venogram (MRV) of the pelvis was done. MRV revealed compression of the left (CIV) 


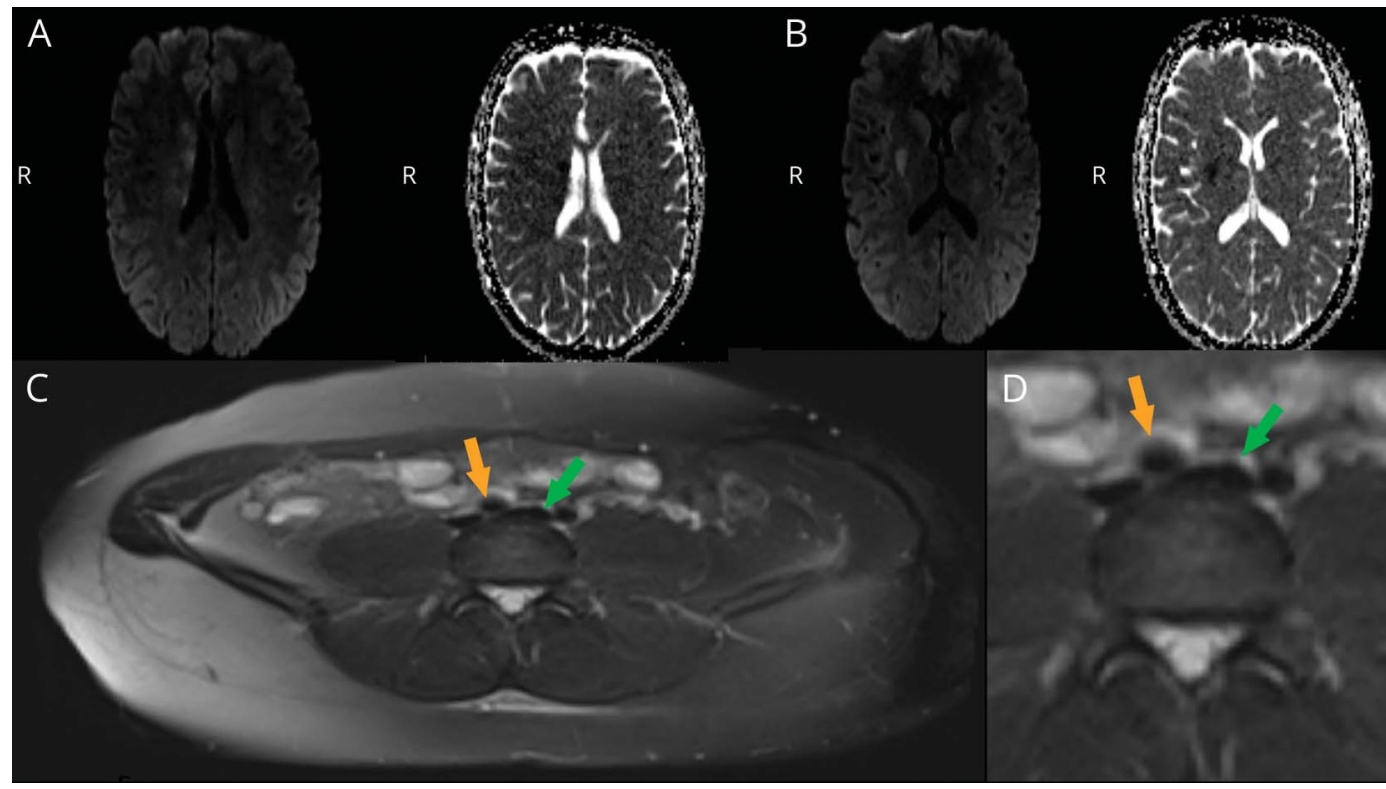

(A, B) Diffusion-weighted imaging and apparent diffusion coefficient sequences of MRI brain show restricted diffusion in the right lentiform nucleus and right corona radiata. (C, D) Magnetic resonance venogram of the pelvis shows compression of the left common iliac vein (green arrow) by the right common iliac artery (orange arrow).

by the right common iliac artery (CIA), without evidence of thrombus (figure, $\mathrm{C}$ and $\mathrm{D}$ ). This finding was believed to be consistent with MTS. The impression was that the patient's stroke was due to paradoxical embolus originating in the iliac vein, perhaps precipitated by venous stasis in the setting of a prolonged car trip. She was started on anticoagulation with apixaban for presumed pelvic DVT.

\section{Discussion}

Embolic strokes of undetermined source (ESUS) comprise $25 \%-33 \%$ of all ischemic strokes ${ }^{1,2}$ and their diagnosis merits the need for conducting a detailed workup directed towards finding the etiology. Efforts should be made to determine the cause, which would lead to a suitable treatment, reducing the possibility of subsequent stroke and disability.

MTS is an anatomical variant where the left CIV is compressed by the right CIA against the lumbar vertebrae. ${ }^{3}$ In 1957, May and Thurner found this variant in $22 \%$ of cadavers. This anomaly causes venous stasis that promotes the formation of thrombi. When accompanied by a PFO, this compression is a possible source of an embolic stroke.

Our patient had an acute stroke with rapid resolution of symptoms, probably due to treatment with IV rtPA, but ischemic changes with an embolic pattern were evident on MRI. Hypercoagulable states related to arterial ischemic events, such as homocysteinemia and antiphospholipid antibody syndrome, were explored, with negative results. Initial workup was significant for a PFO with ASA. A PFO is a common anatomical variant, present in approximately $25 \%-27 \%$ of the normal population. ${ }^{4,5}$ Moreover, prevalence is higher in patients with ESUS, which suggests that paradoxical embolism could be the pathologic mechanism causing the stroke in many of these cases. ${ }^{6}$ A meta-analysis of 17 studies found that the odds of finding a PFO in a patient with ESUS are almost 3 times higher than in patients with stroke with a known cause. ${ }^{7}$ However, given its high prevalence in the general population, it is often difficult to ascertain whether a PFO relates to the stroke mechanism or is incidental. For this purpose, a scoring tool has been proposed: the RoPE score can help determine whether the PFO is incidental or is significant in the etiology of the stroke. ${ }^{8}$ Younger patients without traditional vascular risk factors will have a higher RoPE score (higher probability of PFO-related stroke). With a RoPE score of 8 , our patient's PFO most likely played a role in her stroke mechanism. This hypothesis is strengthened by the accompanying finding of an ASA, which has a stronger association with ESUS. ${ }^{9}$ The next step was locating a source for the embolus. Lower extremity Doppler was negative for DVT. Hypercoagulable panel was extended to hypercoagulable states usually related to venous thromboembolism, including antithrombin III, factor V Leiden, protein C, and factor VIII, which were all negative. Due to strong suspicion of a thromboembolic venous event as the cause of stroke, imaging was extended proximally, with an MRV of the pelvis. Pelvic vascular anatomy was consistent with MTS. A thrombus was not seen on the MRV, likely because it had already embolized completely. 
Few studies have addressed the prevalence of PFO coexistence with MTS. Two retrospective studies of patients with ESUS and PFO found a prevalence between 6\% and 8\% for MTS, with most of them being young female patients. ${ }^{10,11}$ Another retrospective study found an increased prevalence of MTS in patients with ESUS (with or without PFO) when compared to a control group of patients having undergone vessel imaging of the pelvis for a different reason. ${ }^{6}$ Furthermore, degree of compression was higher in the ESUS group. These findings suggest that MTS should be considered in the differential diagnosis of patients with ESUS, particularly in those with a high suspicion for paradoxical embolism given by a high RoPE score, such as our patient.

After a stroke mechanism was found, the next step was to initiate therapy that would prevent subsequent strokes in our patient. There is debate regarding benefit of PFO closure in patients with ESUS. Initially, 3 clinical trials did not find differences in stroke recurrence between patients undergoing PFO closure when compared to those receiving medical therapy. ${ }^{12-14}$ Furthermore, risk of procedure-related complications ranged from $0 \%$ to $4.2 \%$ across the trials. ${ }^{12-14} \mathrm{~A}$ pooled analysis from these trials found benefit in the closure group. ${ }^{15}$ However, there was significant heterogeneity in the medical therapy group, as these patients received either antiplatelet or anticoagulant therapy. Recently, results from 3 randomized trials supported PFO closure to reduce recurrent strokes in patients with paradoxical embolism. ${ }^{16-18}$ Nevertheless, current American Heart Association guidelines do not support PFO closure in patients with ESUS. ${ }^{19}$ American Heart Association/American Stroke Association guidelines recommend anticoagulation in patients with ischemic stroke and a venous source of embolism, which is probably the mechanism in this patient. ${ }^{19}$ Therefore, anticoagulation was started as a treatment, to avoid formation and subsequent embolization of another clot in the compressed iliac vein. ${ }^{20}$

When faced with ESUS in a patient in whom a PFO is documented, workup should be directed towards ruling out causes of paradoxical embolism. MRV pelvic imaging is a useful noninvasive diagnostic tool to assess for thrombus and abnormal anatomy. Discovery of MTS affects clinical decision-making and thus, pelvic imaging should be pursued in patients with ESUS who are found to have a PFO and a high RoPE score. This case illustrates that strong consideration should be given to expanding the standard current diagnostic approach in select ESUS patients to include MRV pelvis imaging as it could better translate into more optimized secondary stroke prevention therapy.

\section{Author contributions}

Andrés De León-Benedetti: intellectual content and original manuscript draft. Erika T. Marulanda-Londoño: intellectual content and original manuscript draft. Amer M. Malik: intellectual content and original manuscript draft.

\section{Study funding}

No targeted funding reported.

\section{Disclosure}

The authors report no disclosures relevant to the manuscript. Go to Neurology.org/ $\mathrm{N}$ for full disclosures.

\section{References}

1. Hart RG, Diener HC, Coutts SB, et al. Embolic strokes of undetermined source: the case for a new clinical construct. Lancet Neurol 2014;13:429-438.

2. Nouh A, Hussain M, Mehta T, Yaghi S. Embolic strokes of unknown source and cryptogenic stroke: implications in clinical practice. Front Neurol 2016;7:37.

3. May R, Thurner J. The cause of the predominantly sinistral occurrence of thrombosis of the pelvic veins. Angiology 1957;8:419-427.

4. Hagen PT, Scholz DG, Edwards WD. Incidence and size of patent foramen ovale during the first 10 decades of life: an autopsy study of 965 normal hearts. Mayo Clin Proc 1984;59:17-20.

5. Meissner I, Whisnant JP, Khandheria BK, et al. Prevalence of potential risk factors for stroke assessed by transesophageal echocardiography and carotid ultrasonography: the SPARC study: Stroke Prevention: Assessment of Risk in a Community. Mayo Clin Proc 1999; 74:862-869.

6. Prabhakar AM, Misono AS, Brinegar KN, et al. Use of magnetic resonance venography in screening patients with cryptogenic stroke for May-Thurner syndrome. Curr Probl Diagn Radiol 2016;45:370-372.

7. Alsheikh-Ali AA, Thaler DE, Kent DM. Patent foramen ovale in cryptogenic stroke: incidental or pathogenic? Stroke 2009;40:2349-2355.

8. Kent DM, Ruthazer R, Weimar C, et al. An index to identify stroke-related vs incidental patent foramen ovale in cryptogenic stroke. Neurology 2013;81: 619-625.

9. Handke M, Harloff A, Olschewski M, Hetzel A, Geibel A. Patent foramen ovale and cryptogenic stroke in older patients. N Engl J Med 2007;357:2262-2268.

10. Kiernan TJ, Yan BP, Cubeddu RJ, et al. May-Thurner syndrome in patients with cryptogenic stroke and patent foramen ovale: an important clinical association. Stroke 2009;40:1502-1504.

11. Osgood M, Budman E, Carandang R, Goddeau RP, Henninger N. Prevalence of pelvic vein pathology in patients with cryptogenic stroke and patent foramen ovale undergoing MRV pelvis. Cerebrovasc Dis 2015;39:216-223.

12. Furlan AJ, Reisman M, Massaro J, et al. Closure or medical therapy for cryptogenic stroke with patent foramen ovale. N Engl J Med 2012;366:991-999.

13. Meier B, Kalesan B, Mattle HP, et al. Percutaneous closure of patent foramen ovale in cryptogenic embolism. N Engl J Med 2013;368:1083-1091.

14. Carroll JD, Saver JL, Thaler DE, et al. Closure of patent foramen ovale versus medical therapy after cryptogenic stroke. N Engl J Med 2013;368:1092-1100.

15. Kent DM, Dahabreh IJ, Ruthazer R, et al. Device closure of patent foramen ovale after stroke: pooled analysis of completed randomized trials. J Am Coll Cardiol 2016;67: 907-917.

16. Saver JL, Carroll JD, Thaler DE, et al. Long-term outcomes of patent foramen ovale closure or medical therapy after stroke. N Engl J Med 2017;377: 1022-1032.

17. Mas JL, Derumeaux G, Guillon B, et al. Patent foramen ovale closure or anticoagulation vs. antiplatelets after stroke. N Engl J Med 2017;377:1011-1021.

18. Søndergaard L, Kasner SE, Rhodes JF, et al. Patent foramen ovale closure or antiplatelet therapy for cryptogenic stroke. N Engl J Med 2017;377:1033-1042.

19. Kernan WN, Ovbiagele B, Black HR, et al. Guidelines for the prevention of stroke in patients with stroke and transient ischemic attack: a guideline for healthcare professionals from the American Heart Association/American Stroke Association. Stroke 2014;45:2160-2236.

20. Buesing KL, Mullapudi B, Flowers KA. Deep venous thrombosis and venous thromboembolism prophylaxis. Surg Clin North Am 2015;95:285-300. 


\section{Neurology}

\section{Pearls \& Oy-sters: May-Thurner syndrome as a cause of embolic stroke of undetermined source in a young patient}

Andrés De León-Benedetti, Erika T. Marulanda-Londoño and Amer M. Malik

Neurology 2019;92;e2507-e2509

DOI 10.1212/WNL.0000000000007541

\section{This information is current as of May 20, 2019}

\section{Updated Information \& Services \\ Supplementary Material \\ References \\ Subspecialty Collections}

Permissions \& Licensing

Reprints including high resolution figures, can be found at: http://n.neurology.org/content/92/21/e2507.full

Supplementary material can be found at: http://n.neurology.org/content/suppl/2020/01/31/92.21.e2507.DC1

This article cites 20 articles, 5 of which you can access for free at: http://n.neurology.org/content/92/21/e2507.full\#ref-list-1

This article, along with others on similar topics, appears in the following collection(s):

\section{Embolism}

http://n.neurology.org/cgi/collection/embolism

MRI

http://n.neurology.org/cgi/collection/mri

Other cerebrovascular disease/ Stroke

http://n.neurology.org/cgi/collection/other_cerebrovascular_disease_s troke

Stroke in young adults

http://n.neurology.org/cgi/collection/stroke_in_young_adults

Information about reproducing this article in parts (figures,tables) or in its entirety can be found online at:

http://www.neurology.org/about/about_the_journal\#permissions

Information about ordering reprints can be found online: http://n.neurology.org/subscribers/advertise

Neurology ${ }^{\circledR}$ is the official journal of the American Academy of Neurology. Published continuously since 1951, it is now a weekly with 48 issues per year. Copyright @ 2019 American Academy of Neurology. All rights reserved. Print ISSN: 0028-3878. Online ISSN: 1526-632X.

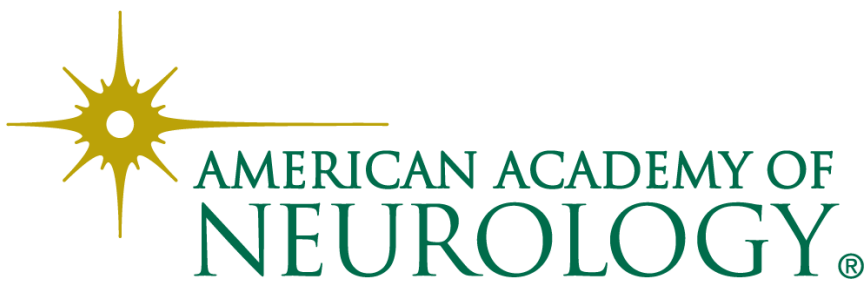

